AGH DRILLING, OIL, GAS • Vol. 35 • No. 1 • 2018

http://dx.doi.org/10.7494/drill.2018.35.1.343

\author{
Andrew K. Wojtanowicz*, Lu Jin**
}

\title{
LOSS AND RESTORATION OF WATER CONING CONTROL - FIELD CASE HISTORY AND PREDICTION
}

\section{INTRODUCTION}

Critical oil rate may be too low to be economically viable in many heavy oil reservoirs with bottom water, so their wells must produce oil with water. However, the unfavorable mobility ratio between heavy oil and water usually causes early water breakthrough and very high water cut, which leads to low oil recovery and massive produced water in the field [1-4]. Ju et al. (2005) [5] reported that the H.K. heavy oil field in China only recovered $1 \%$ original oil in place (OOIP) when the water cut was 90\% [5]. Canada has a large quantity of heavy oil reserves in Alberta and Saskatchewan, where many reservoirs are underlain by large aquifers. Similar to the H.K. oil field, primary oil recovery from those reservoirs is very low - from 1 to $5 \%$ when water cut approaches to $100 \%$ [6-8]. The same problem also troubles many offshore heavy oil fields located in the U.K. continental shelf, offshore Brazil, and Bohai Bay in China etc. [9-12]. Since the gravity difference is small between the heavy oil and produced water, it is difficult to separate them in the limited volume of offshore facilities. As a result, both solids and water droplets to remain in suspension, leading to heavy oil emulsions with water [13]. Horizontal wells have been used to produce oil from these offshore heavy oil reservoirs, and many field cases have demonstrated the advantages of the horizontal wells compared to the vertical wells [14-18]. However, horizontal wells also face technical, environmental, and economic challenges in oil-water treatment and water disposal caused by water cresting problem [19-24].

Many different methods have been developed to control the water coning/cresting problems in heavy oil reservoirs, however, few of them can solve the problem satisfactorily.

* Louisiana State University
* University of North Dakota 
Operators tried to complete the wells as close to the top of the reservoir as possible to delay water breakthrough, but in many cases, water still breakthrough to the wells quickly due to the high mobility ratio between oil and water [10]. Downhole oil water separation can separate the water from the oil using hydrocyclones, lift oil to the surface, and the excess water into a disposal zone. However, this technology requires a complex downhole system in the well and a suitable water disposal formation under the reservoir, which limit its application in field operations [25-30].

Many successful field cases indicated that heavy oil could be produced effectively from reservoirs with bottom water by pumping water from the aquifer to reduce aquifer pressure and reduce strength of water drive [31-33]. Similar mechanism is employed in the DWS technology for local control of water coning [34]. Generally, a DWS well has two completions: the top completion is installed in the oil pay zone to produce oil, and the bottom completion is placed in the aquifer to keep the oil water contact (OWC) beneath the top completion [35-40]. To date, various versions of DWS technique have been developed by the Downhole Water Sink Technology Initiative (DWSTI) research program at the Louisiana State University (LSU) - including Downhole Water Loop (DWL), and Bilateral Water Sink (BWS) etc. to make the DWS technology applicable to different types of reservoir-aquifer systems [41-48].

The objectives of this study is to investigate the feasibility of DWS for water coning control and oil productivity improvement in a heavy oil reservoir with bottom water using a field case data and reservoir simulation with the following objectives:

1. Efficiency of a simplified packer-less DWS well with fluid communication between two well completions through gravel pack.

2. The effect and physical mechanism of temporary water sink completion shut-down.

3. Possible revival of "watered out well" - remediation of well productivity loss due severe water coning.

4. Effect of the bottom aquifer strength (water drive) on DWS performance contribution of the bottom water drive (aquifer strength) to the restored productivity.

\section{FIELD CASE BACKGROUND}

The TB oil reservoir reported by Wojtanowicz and Qin (2010) [2] is a heavy oil reservoir with unconsolidated sands, where the T-sands of Paleocene age and of fluvial-estuarine to coastal marine of origin at average depths of 900 to $1200 \mathrm{ft}$. The T-sands consist of vertically stacked sand bodies occasionally interbedded with clay and lignite. The sand body pinches out to the South and forms a stratigraphic trap, while to the North it dips about $1^{\circ}$. The thickness of the oil-bearing sands varies from $0 \mathrm{ft}$ up to $45 \mathrm{ft}$ and the sand distribution is very irregular. The sands consist of mostly quartz (95\%) and feldspar (5\%). The sands are strongly heterogeneous and unconsolidated: very fine to coarse grained and poorly to well-sorted through the reservoir. The T-sand reservoirs comprise lower 
reservoir unit, the T-I sand, middle T-2 sand and an upper T-3 sand. The T- 1 sand is characterized by moderately to well-sorted, medium to coarse grain sands, and this sand is the main pay zone (10-24 ft) addressed in this study. Due to an aquifer below the T-1 sand, water coning was identified as a severe problem in this reservoir. It was reported that water cut increased quickly to $90 \%$ after water breakthrough to the producers.

Therefore, oil production with conventional single-completed wells in the TB reservoir is very inefficient. Since 2008, several studies have been conducted and a pilot well was drilled to test the applicability of DWS technology for improved production and recovery performance of wells located in the reservoir section with bottom water. Initial testing of the pilot well determined that DWS was technically feasible.

\section{PACKER-LESS DWS WELL}

A DWS pilot well was drilled in the T-1 sand in 2011. Initially, the well was dualcompleted without isolation between the top and bottom completions as shown in Figure 1. Oil was produced from the top completion above OWC using an individual production tubing. Water was drained via another production tubing from the bottom completion below the OWC.

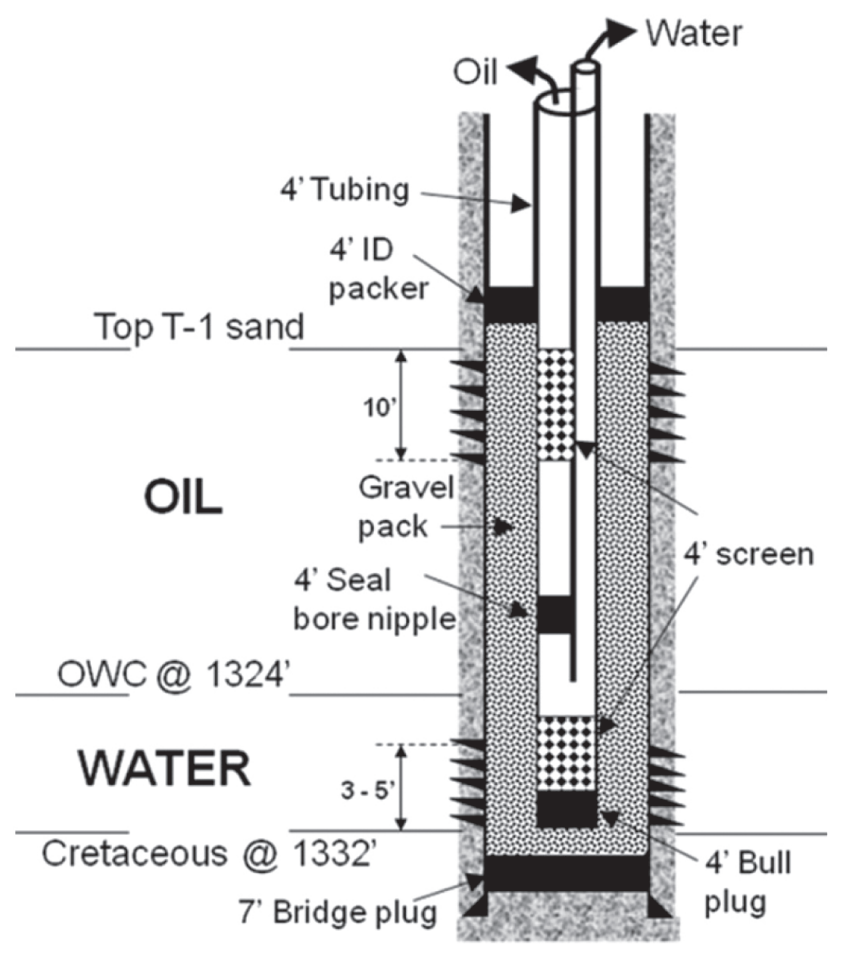

Fig. 1. Schematics of DWS well with packer-less dual completion 
Performance of water cut in the top completion and oil cut in bottom completion is shown in Figure 2, which clearly indicates that draining water in the bottom completion cannot continuously the water production in the top completion: the water cut at top completion increased to $80 \%$ over the 5-month test period. As there was no isolation between the top and bottom completions, fluid communication became unavoidable, and also certain quantity of oil broke into the bottom completion due to the pressure drawdown created by water drainage. The green line (2) in Figure 2 clearly shows that oil cut was quite stable (3\%) during the 5-month test. Although the test results demonstrated the functionality of DWS for water coning control, the problem of fluid communication between the two completions should have been solved.

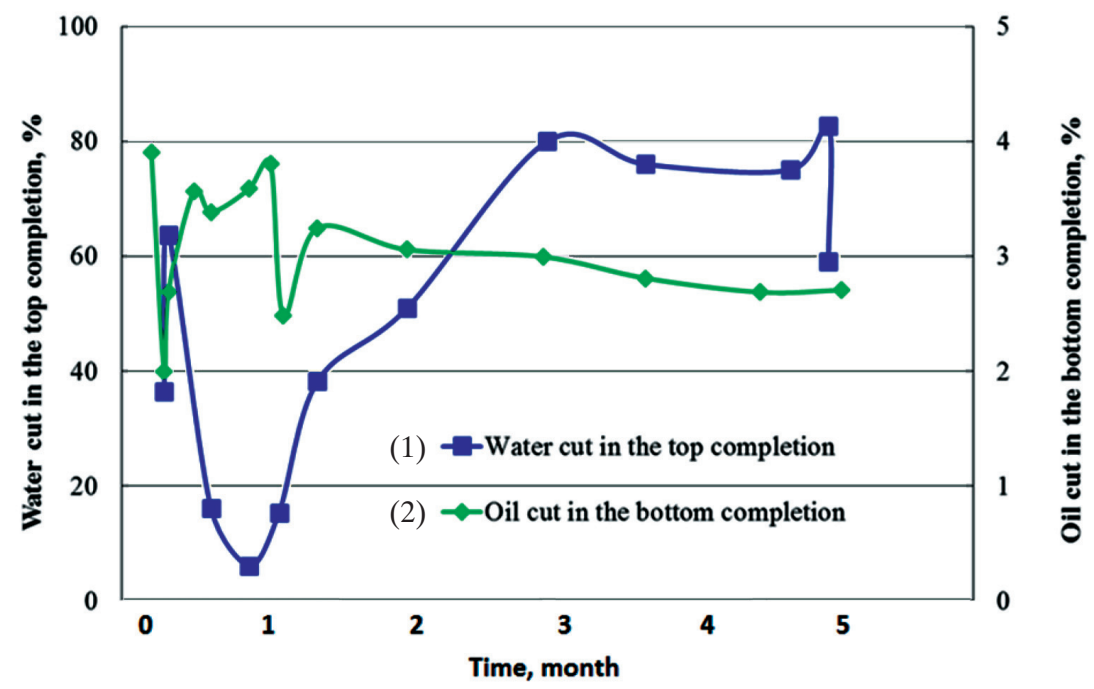

Fig. 2. Water and oil cuts in top and bottom completions of the DWS

\section{PERFORMANCE OF DWS WELL WITH PACKER}

Due to the high oil cut in the bottom completion, the DWS well was re-completed in with an isolation packer between the completions (see Fig. 3). Well performance, prior to recompletion and after the recompletion is shown in Figures 4-8. The recompleted well performance covers the time period from 44.3 to 57.5 months. After installing the packer, oil production stabilized at about 18 bopd for almost a year (Fig. 6) while water rate and water cut actually reduced from 10 to 5 bwpd and $30 \%$ to $20 \%$, respectively (Figs. 7 and 8 , respectively). Unfortunately, after over a year of stable production (month 57.5), the DWS well bottom (sink) water drainage from the sink completion was stopped (for downhole pump maintenance) while the top completion kept on producing, which lead to almost immediate water cut increase to $100 \%$ so the well "watered out" and was, consequently, shut down. 


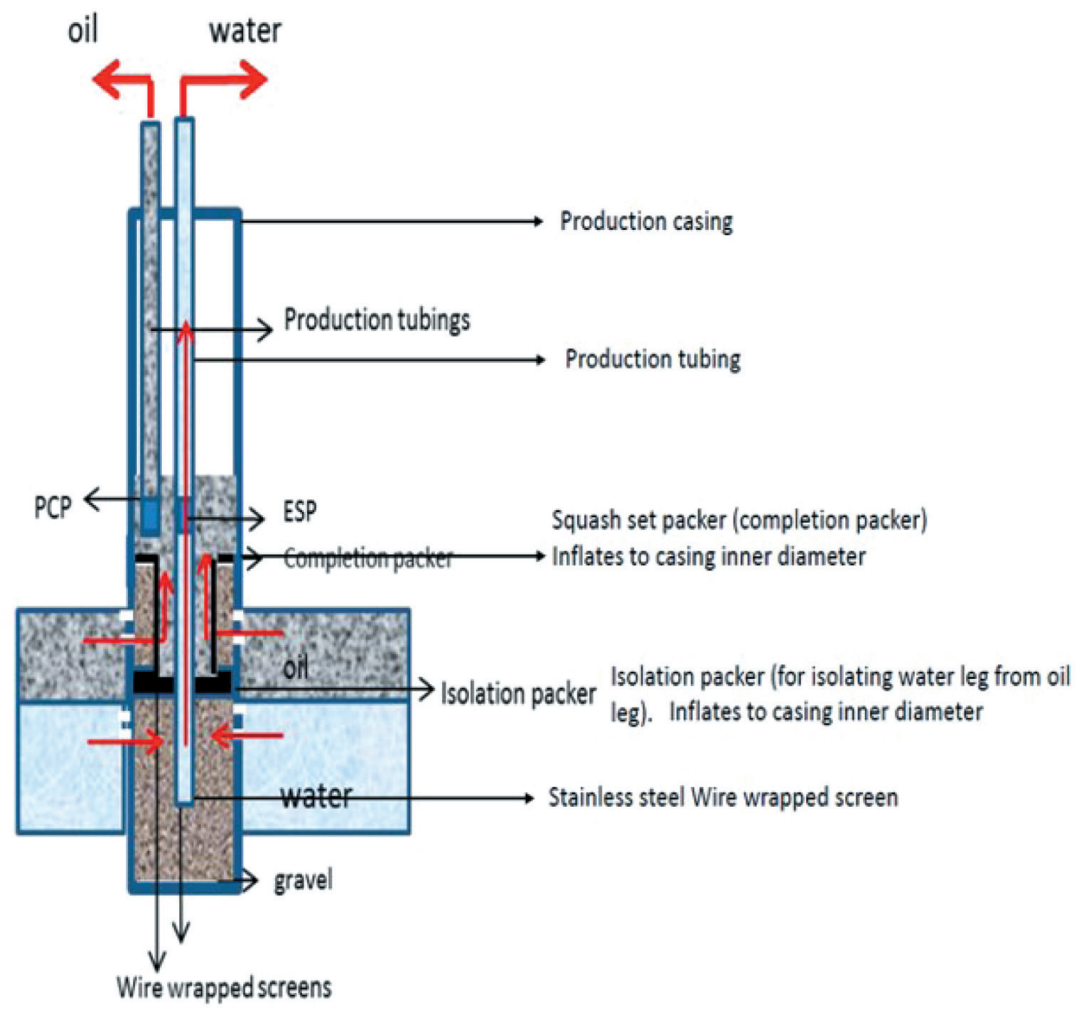

Fig. 3. Schematic of re-completed DWS in the T-1 sand

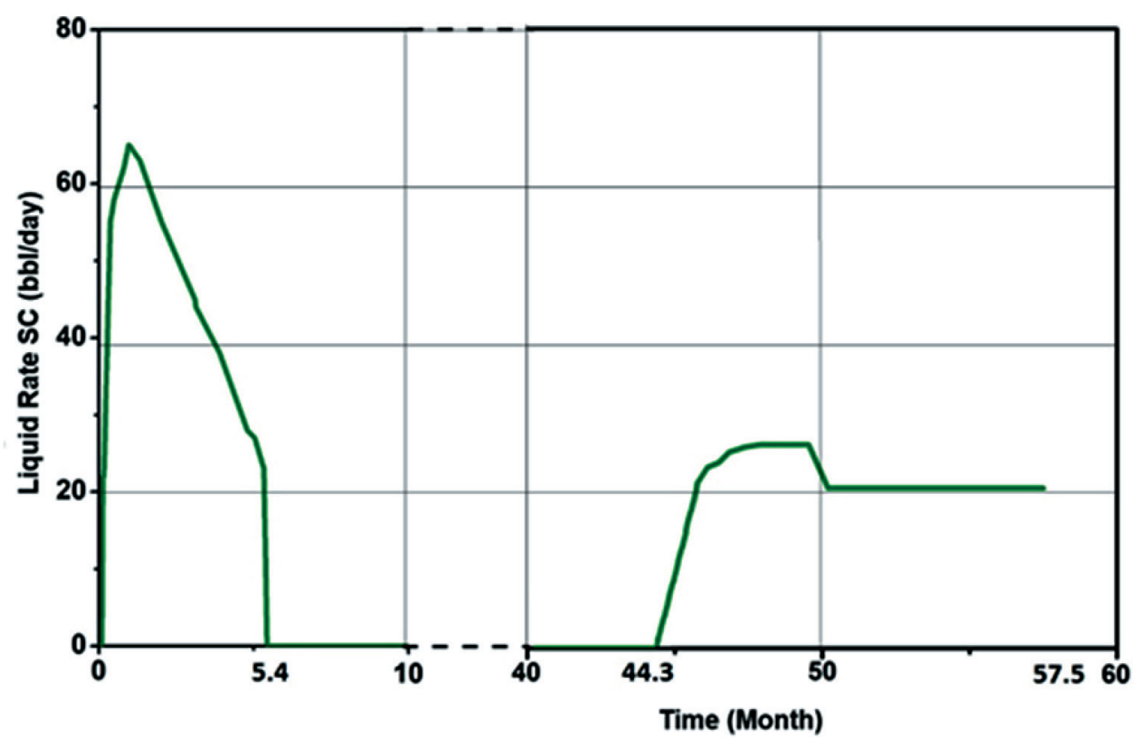

Fig. 4. DWS well top completion liquid oil rate before and after re-completion 


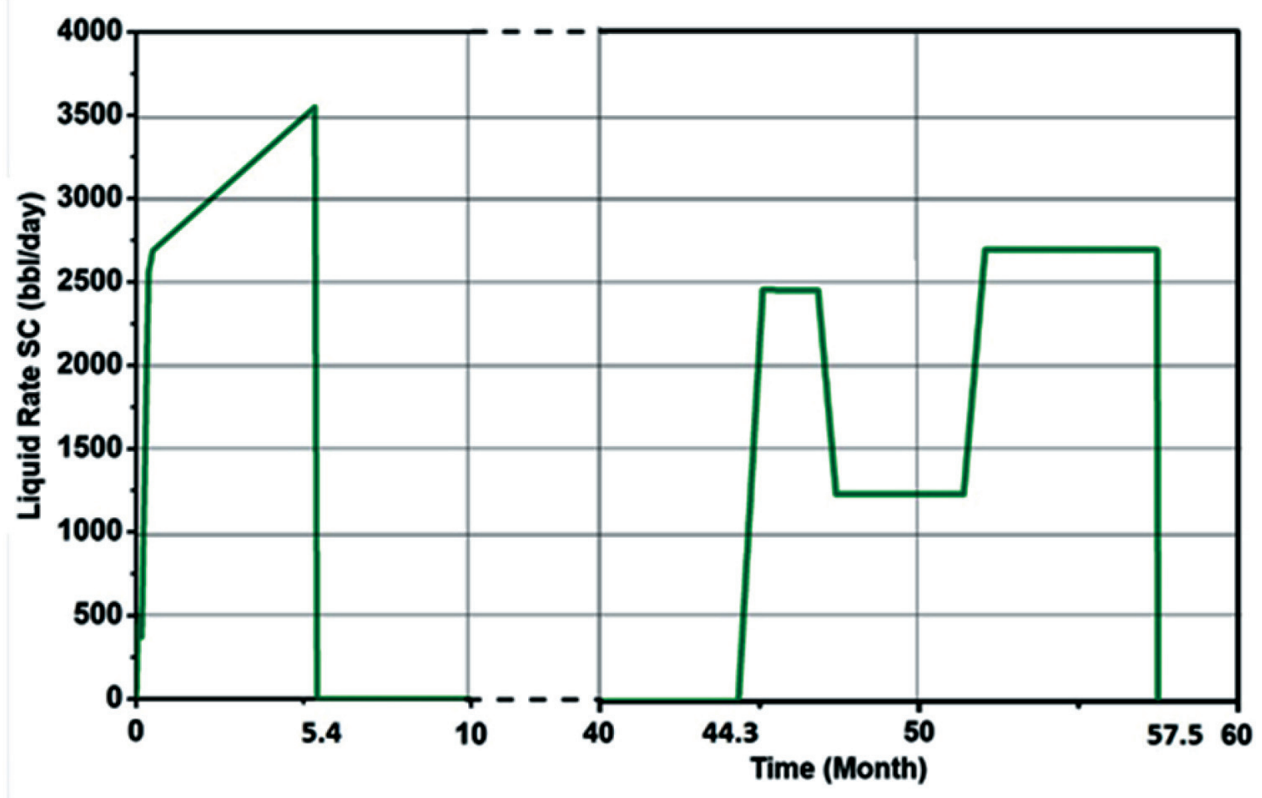

Fig. 5. DWS well sink completion liquid rate before and after re-completion

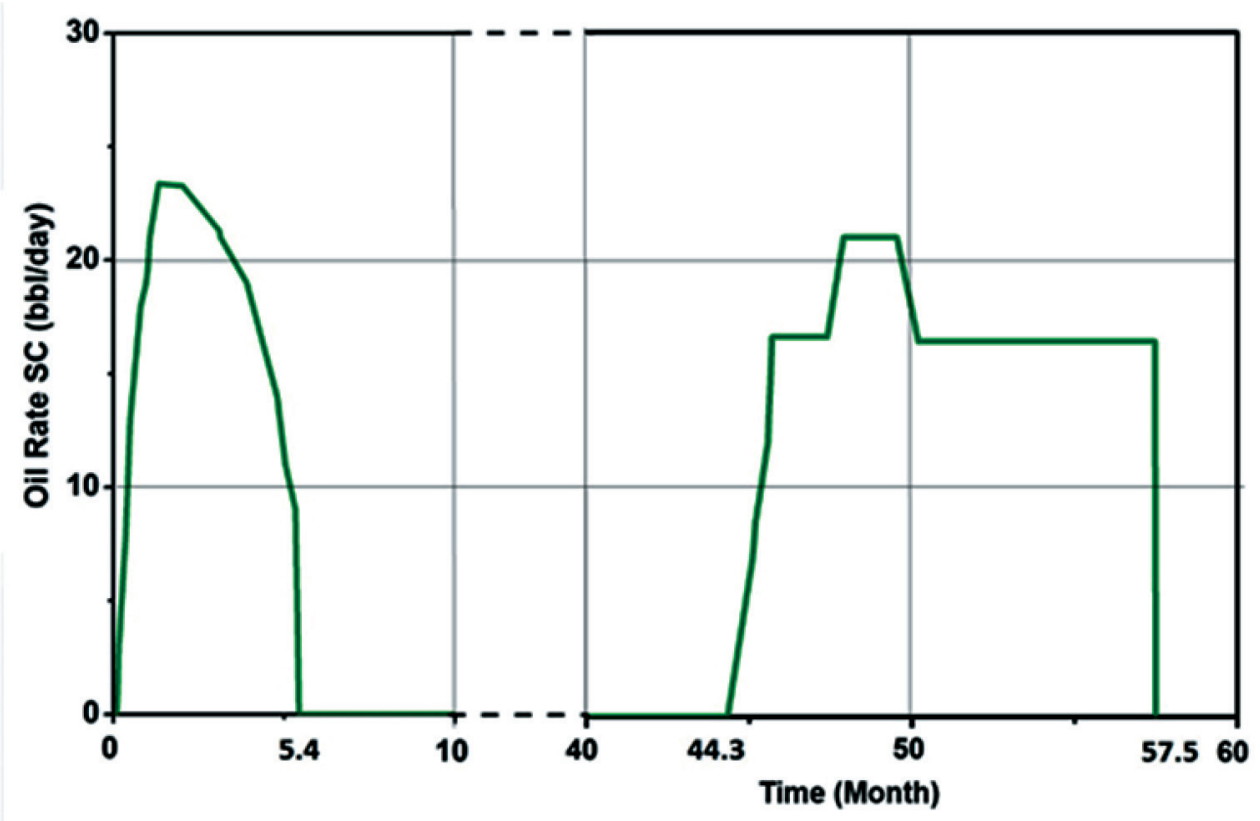

Fig. 6. DWS well top completion oil rate before and after re-completion 


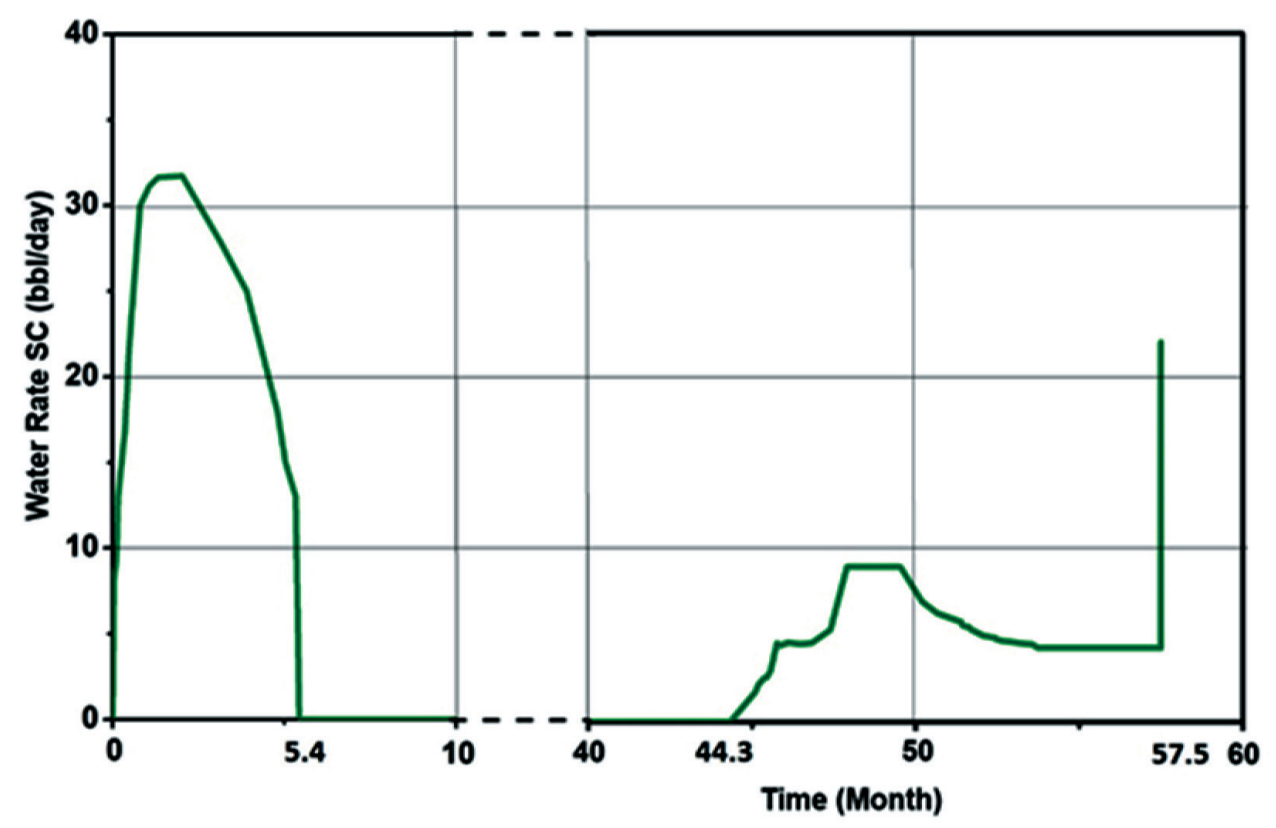

Fig. 7. DWS well top completion water rate before and after re-completion

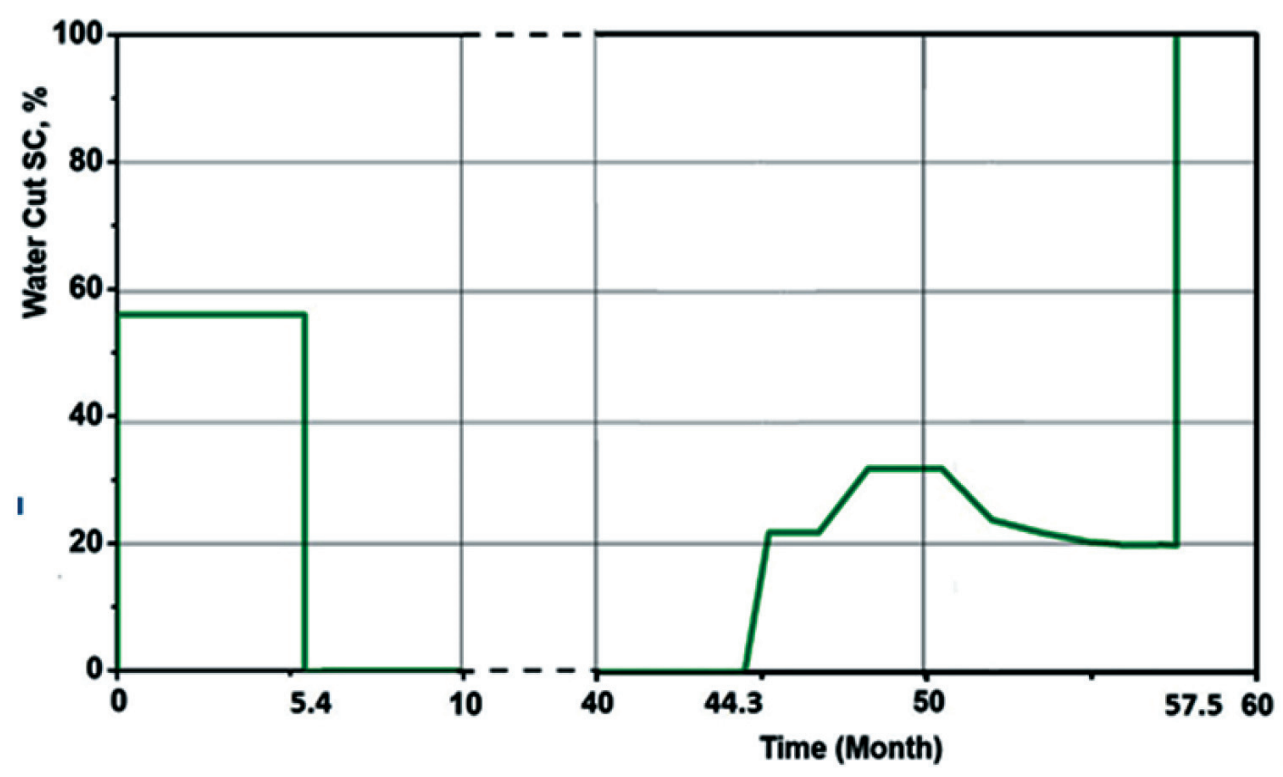

Fig. 8. DWS well top completion water cut before and after re-completion 
The performance of the recompleted well clearly shows that even severe water coning can be effectively controlled using dual-completed DWS well with isolating packer. It also demonstrates detrimental effect of sole temporary cessation of water drainage from the sink completion with continuing production from the top completion.

\section{NUMERICAL ANALYSIS OF DWS WELL PERFORMANCE FAILURE}

Numerical simulation was used to gain physical insight of the DWS well productivity failure. The available DWS well's production record was history-matched using reservoir simulator.

Since it is an un-consolidated heavy oil reservoir with considerable bottom water drive, high oil/water mobility ratio results in a buildup of water cone close to the well. In such case, radial grid model is a better option to capture the local coning profile. In this study, we built a simplified model with radial grids to conduct history match and reduce the uncertainty in parameter evaluation. The model, Figure 9, was constructed with 308 logarithmic radial grids $\left(11^{*} 1 * 28\right)$ - the smallest grid, $0.54 \mathrm{ft}$ is next to the well, and the grid size at the aquifer's outer boundary is $20,000 \mathrm{ft}$. The large grid size is used for aquifer only and it is disabled in the oil zone. The grid sizes in vertical direction vary from $1 \mathrm{ft}$ to $60 \mathrm{ft}$. The horizontal permeability for the oil zone and the first $7 \mathrm{ft}$ of the aquifer (including the possible transition zone) is set as 10,000 md, and the vertical permeability is 7,000 md. The remaining 93 feet of the aquifer has horizontal and vertical permeabilities of $100 \mathrm{md}$ each. Since there is no detailed data on aquifer properties, we estimate its permeability based on the well logs and available core data. The total thickness of the aquifer is set at $100 \mathrm{ft}$ in the model.

In DWS wells, reverse coning (i.e. oil cones to the aquifer) is usually possible when the water drainage rate is high enough to suppress the pressure drawdown in the oil zone. Therefore, two sets of relative permeability with capillary pressure curves are used, one for the oil zone and another for the aquifer. In fact, curves in aquifer may be impacted more by oil invasion since residual oil saturation is induced in the aquifer sand saturated with only water originally. The gravel pack is simulated with high permeability within the innermost cylindrical grid with both the horizontal and vertical permeability values equal to 120 Darcy. Oil viscosity is set as $300 \mathrm{cp}$ at $344 \mathrm{psi}$ and 1395 at 50 psi based on the PVT report and production rate/pressure relationship.

The history match was performed for all periods of different DWS well operation shown in Figures $4-8$. The first period covers production with the packer-less completion for 5.4 months and the well's idling until 44.3 months. The second production period of the re-completed well (with a packer) took place from 44.3 months through 
57.5 months followed with a one-month well shutdown that was also considered in the history match. Since the available production rate record was quite scattered and there was no record of bottom pressure, we only matched well production history.

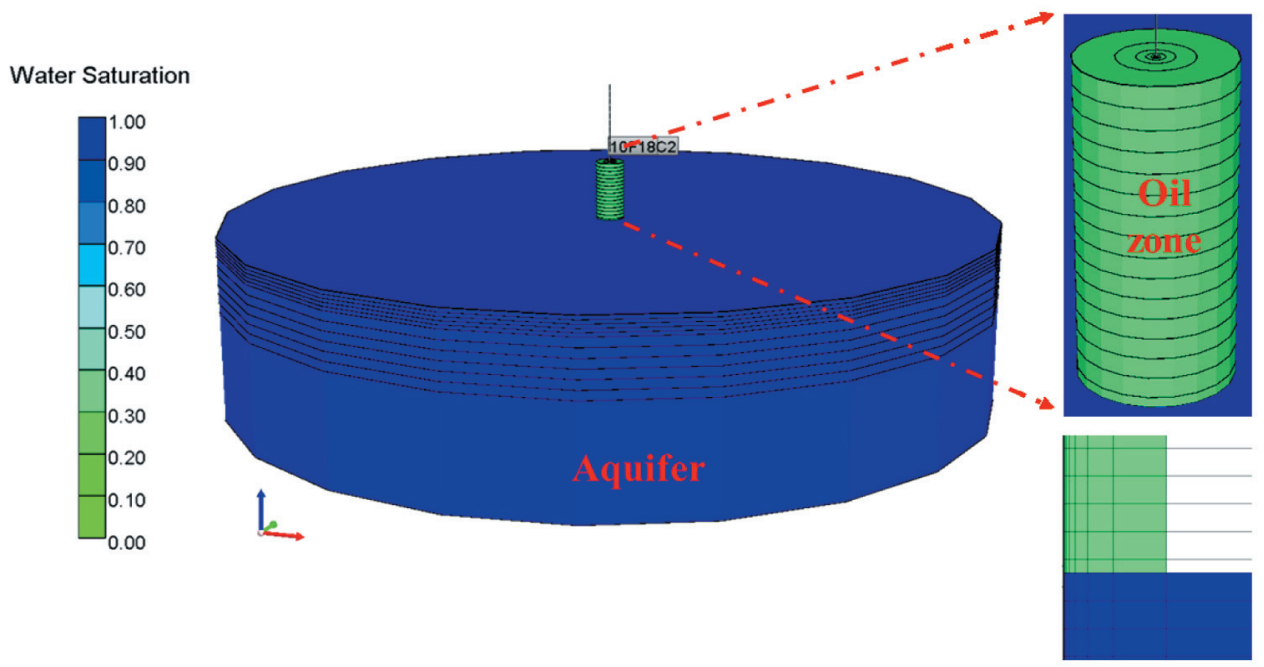

Fig. 9. Radial- grid model of DWS well

The well's re-completion (at 44.3 months) involved another gravel packing operation and installation of an isolation packer between the top and bottom completions. Therefore, history matching involved adjustment of gravel pack size and permeability and addition of impermeable grids between the two completion intervals. Moreover, a considerable adjustment of the relative permeability and capillary pressure curves, shown in Figures 10 and 11, had to be made to match the production history after the well's re-completion - particularly within the aquifer zone.

a)

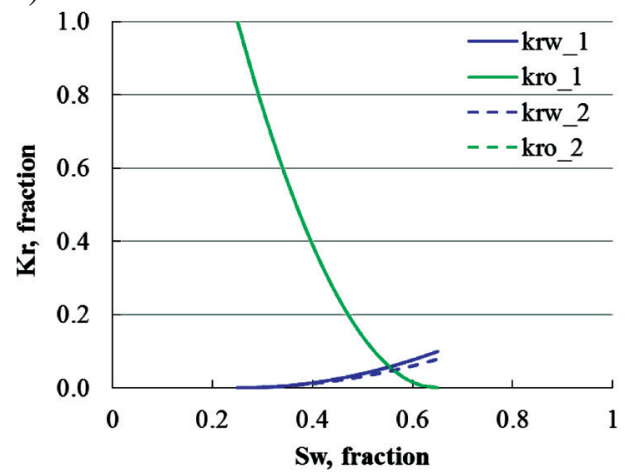

b)

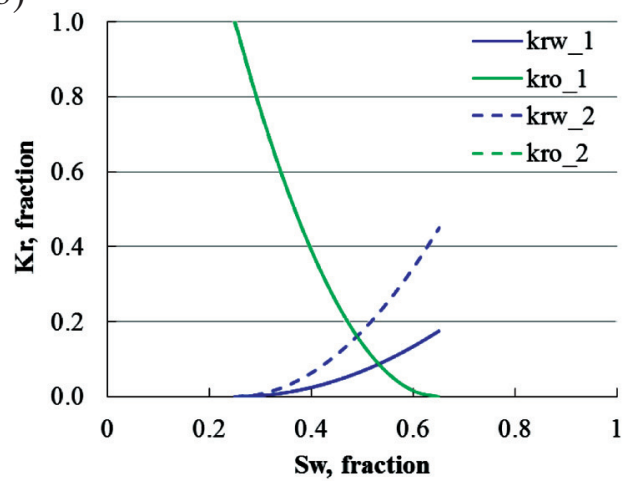

Fig. 10. Relative permeability plots in the oil (a) and water (b) zones 
a)

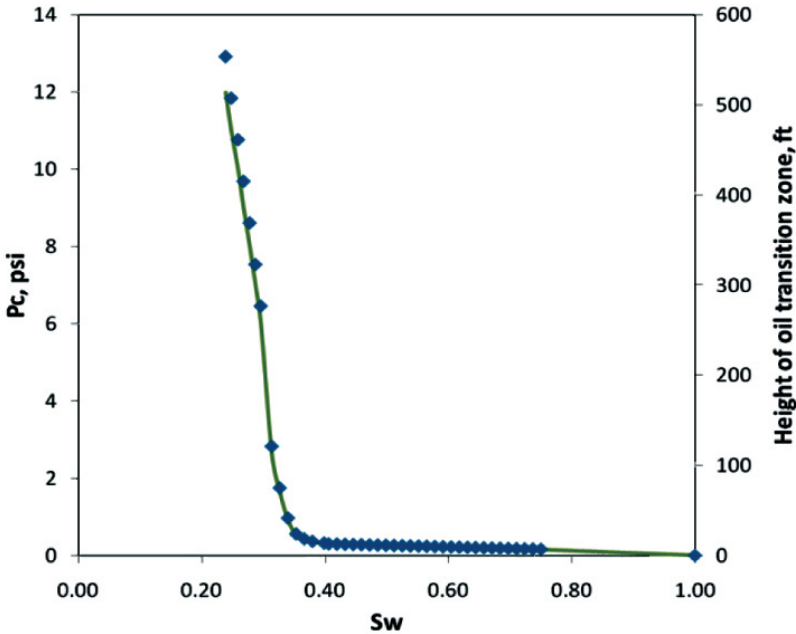

b)

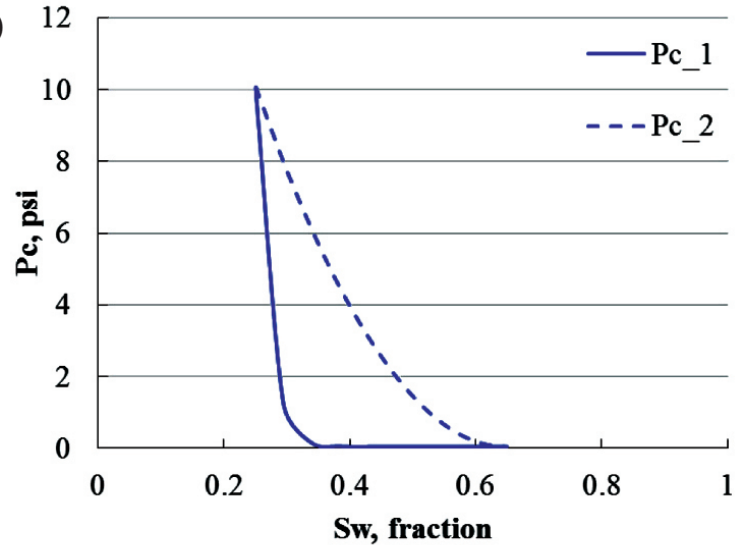

Fig. 11. Capillary pressure plots in the oil (a) and water (b) zones

Since the T-1 sand is unconsolidated, the flow properties - permeability, relative permeability and capillary pressure, may change during production due to the change of fluid saturation and pressure. This change would also occur in consolidated reservoirs, but is more severe in un consolidated reservoirs. High water drainage rate at the bottom completion and the resulting pressure drawdown may cause sand grains re-sorting, re-distribution of pore size, and permeability change of the sand in the near-wellbore region, where the relative permeability and capillary pressure curves may be altered. Another possible reason may be the impact of production in the nearby wells, which could also change the pressure and saturation profile around the well.

The DWS well simulation model is used to demonstrate physical mechanism of rapid water cut increase and watering out the DWS well after bottom completion shut-in 
at 57.5 months. As depicted in Figure 12, there is a very prompt and severe water invasion into the oil pay zone around the well. It follows that a conventional single - completed well in this reservoir would not produce any oil but water. Thus the DWS dual completion becomes essential for oil recovery in this reservoir. Moreover, potential restoration the well's oil productivity might require a resting time period after the shut-in of the oil leg - so no more water is produced. During the resting time period, gravity forces could reduce the water saturation around the top completion due to the re-balanced distribution of oil and water in the water coning area.
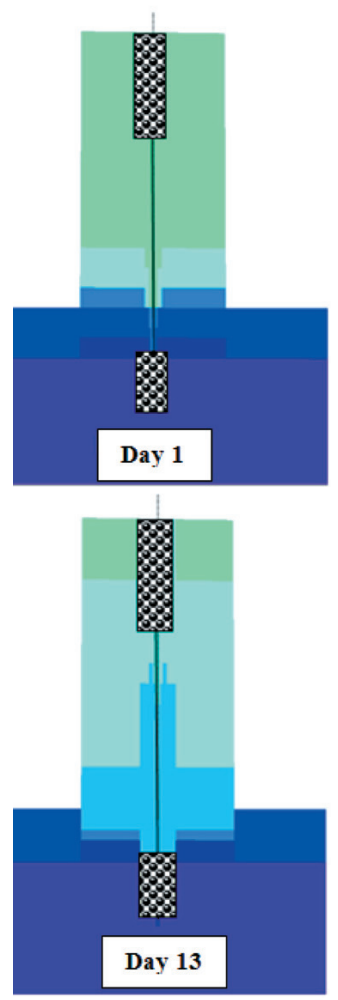
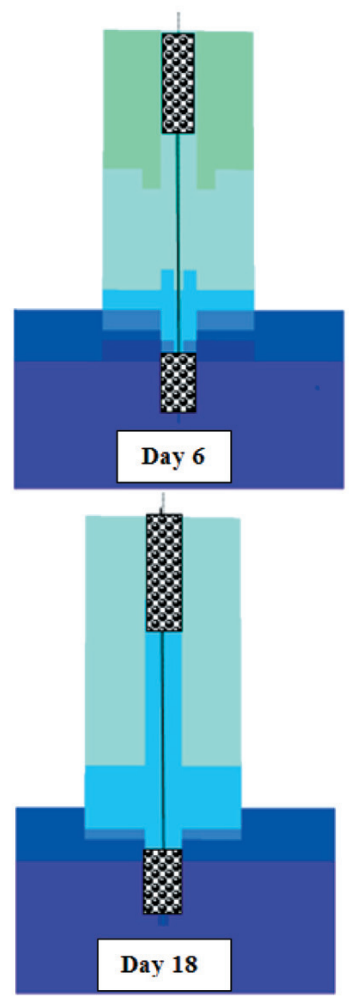

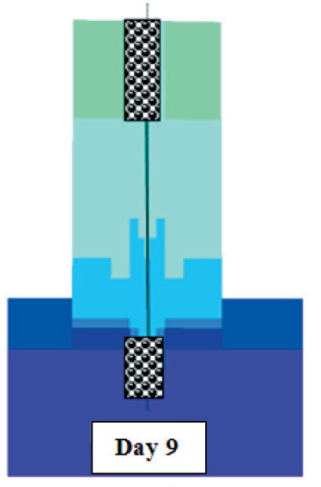

\section{Water Saturation}
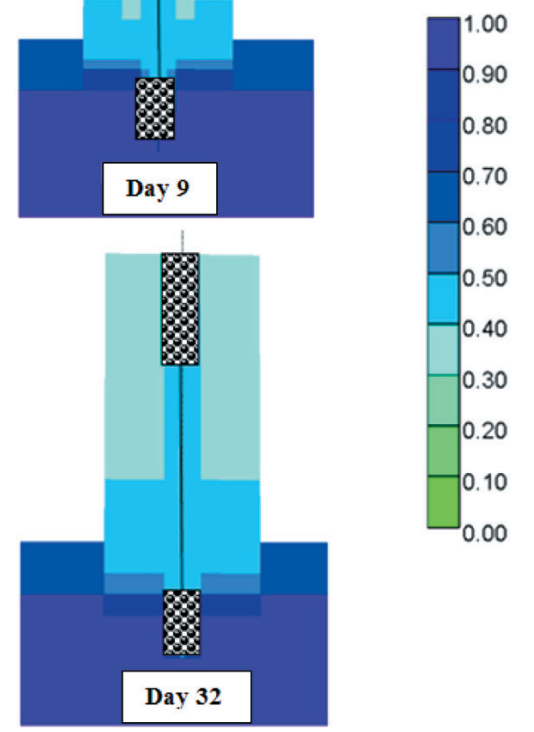

\author{
(a)
}


pressure and well production performance. Two aquifer sizes: 20,000 ft and 200,000 ft, are used to represent weak and strong aquifers in the model. For each aquifer case, three scenarios for the future operation of the DWS well, starting at 57.5 months, are considered:

(a) After watering out at 57.5 months, the well is rested for one month (no production) and, then, it is converted to a conventional well with the top completion producing at $20 \mathrm{bpd}$ liquid rate for 25 years.

(b) After watering out at 57.5 months, the well is not rested but returned to DWS operation with both completions opened and operated at 20 and 2500 bpd liquid rates in the top and bottom completions, respectively, for 25 years.

(c) The bottom (sink) completion is not shut down at 57.5 months so the DWS well continues production from 57.5 month onwards with both completions open and operated at 20 and 2500 bpd liquid rates in the top and bottom completions, respectively, for 25 years.

Oil production forecasts for the weak (Fig. 13) and strong (Fig. 14) cases clearly demonstrate inability to produce this reservoir with conventional wells that practically become water wells. The DWS well does restore oil production but would produce about 10 percent less oil due to accidental shutdown of the sink completion (case b) comparing to operation without the accident (case c). Moreover, when aquifer is small and water drive is weak oil production rate cannot be maintained over the project life, as shown in Figure 13, since the average reservoir pressure drops steadily due to the high water drainage rate and aquifer depletion. Also, when reservoir pressure drops below the bubble point, oil viscosity increases quickly, so less oil could be produced with the same pressure drawdown. In contrast, pressure support from the aquifer would be enough to maintain the oil production rate when the aquifer is large (strong) as shown in Figure 14, therefore higher oil recovery factor could be possible as shown in Figure 15. The reason why constant oil rate value is maintained with large aquifer case is that water drainage from the bottom (sink) completion generates enough pressure drawdown to control water coning around the top completion as shown in Figure 16. Comparison of the water saturation maps in Figure 16 and Figure 14 clearly demonstrates effective removal of water saturation beneath the well pumping water at the sink completion. Water saturation in the coning area could be somewhat reduced due gravity by shutting down the oil leg and letting the well rest for some time with no production. However, the effect is much smaller than draining water in the water leg. In all, restoration of oil productivity in the watered-out well can only be achieved if water coning is reversed hydro-dynamically by the bottom water drainage that effectively removes water saturation from around the well. 


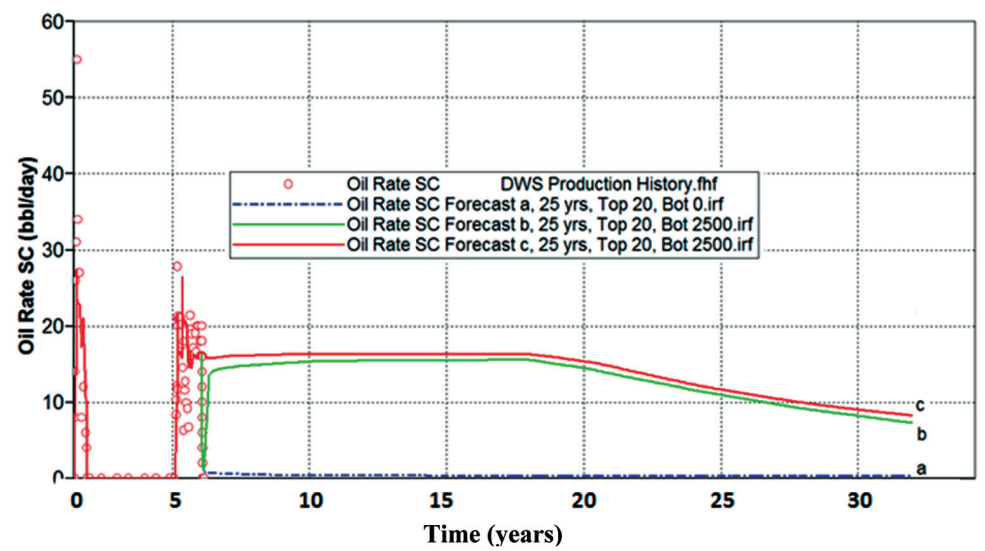

Fig. 13. A 25-year oil production forecast with weak bottom aquifer

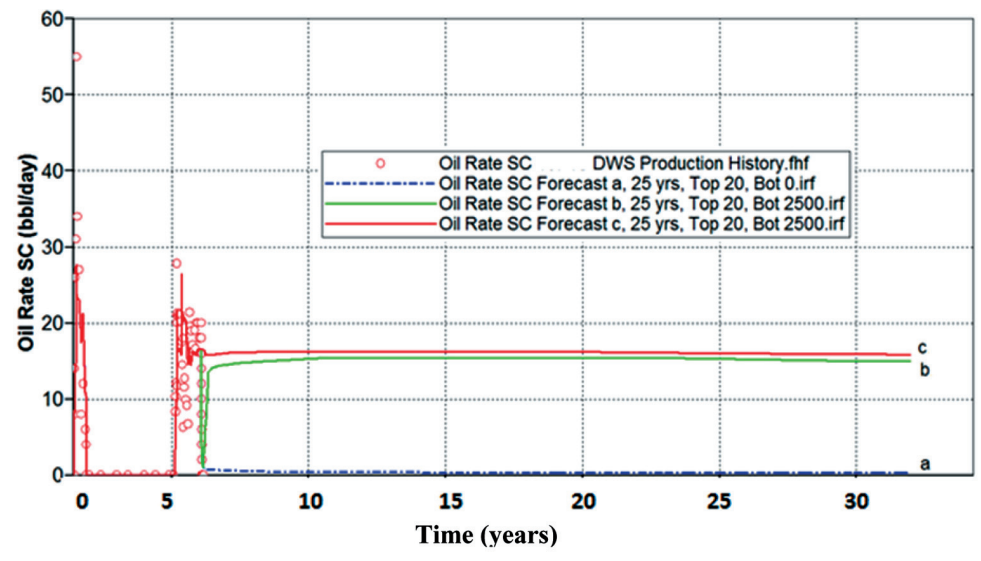

Fig. 14. A 25-year oil production forecast with weak bottom aquifer

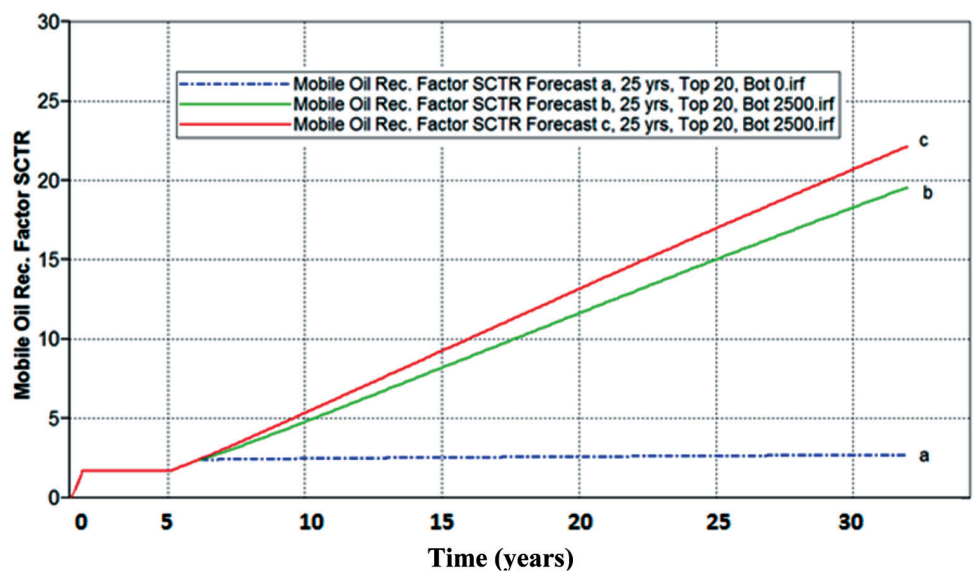

Fig. 15. A 25-year oil recovery forecast with strong bottom aquifer 


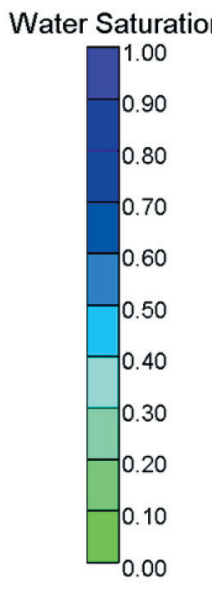

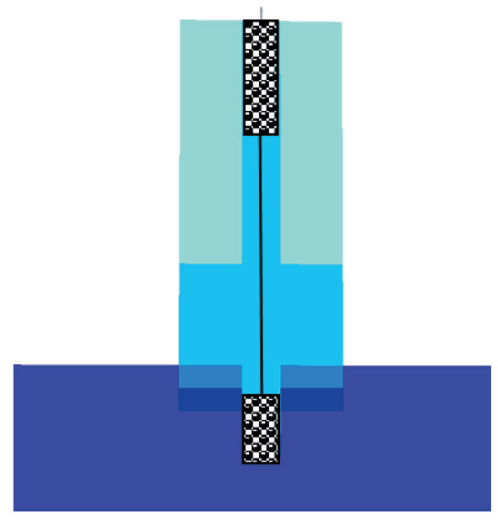

Weak aquifer

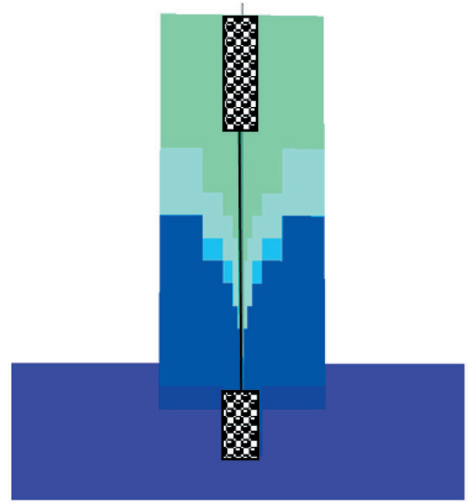

Strong aquifer

Fig. 16. Water saturation maps after 25 years for case (b) with weak and strong aquifer

\section{CONCLUSIONS}

The simulation study demonstrates the modeling and simulation process to mimic the water coning problem and its control by DWS well in the TB heavy oil reservoir. DWS could help to produce more oil in the top completion by draining water in the bottom completion. However, the effects of water coning control and oil production improvement strongly relate to the reservoir properties and aquifer size due to the large oil/water mobility contrast in this heavy oil reservoir. Based on history match and production forecast in different time frames, the findings are summarized as follows:

1. A radial-grid-based simulation model has been developed for the DWS wells in the T-1 sand using the reservoir and production data. The model is able to match the production history with a reasonable accuracy.

2. The results show that DWS operation would make the well productive comparing to conventional (single completed) well that would produce only water.

3. DWS could control water coning using sufficient water drainage rate in the bottom completion, the oil production rate at the top completion is sensitive to the bottom rate.

4. Severe water coning promptly develops around the DWS well when only water sink completion is shut-in- resulting in total loss of well's productivity.

5. 25-year forecasts have been conducted for a few DWS operational scenarios and different aquifer sizes. Results show that DWS performs better when aquifer is strong and there is no interruption during the operation. 
6. DWS recovers more oil in reservoir with strong bottom water drive. This study shows $19-22 \%$ recovery and $16.5-18.5 \%$ recovery with strong and weak aquifer. It also shows recovery about $10 \%$ recovery reduction for a DWS well that has been accidently mismanaged by temporary cessation of water sink drainage and continuing production from the well's top completion.

\section{REFERENCES}

[1] Qin W.: Analytical design method for cold production of heavy oil with bottom water using Bilateral Sink Wells. Ph.D. Dissertation in Louisiana State University, Baton Rouge, LA, 2011.

[2] Wojtanowicz A.K., Qin W.: Improved recovery of heavy oil with bottom water using downhole water sink (DWS) technology. Wiertnictwo, Nafta, Gaz, 27, 2010, pp. 467-84.

[3] Yu H., Li L., Zheng J., Fu X., Ji W., Gao W., Liu H.et al.: Case Study of Blocking Water Coning in Horizontal Well for Steam Stimulation in Heavy Oil Reservoir. In: SPE Asia Pacific Oil \& Gas Conference and Exhibition. Society of Petroleum Engineers, 2016.

[4] Zaitoun A., Kohler N., Montemurro M.A.: Control of water influx in heavy-oil horizontal wells by polymer treatment. In: SPE Annual Technical Conference and Exhibition. Society of Petroleum Engineers, 1992.

[5] Ju B., Dai S. et al.: An Effective Method to Improve Recovery of Heavy Oil Reservoir with Bottom Water Drive. In: Paper SPE 10521-MS, International Petroleum Technology Conference, Doha, Qatar, November 21-23, 2005.

[6] Ali S.M.F.: Prospects of EOR Techniques in Saskatchewan Oil Reservoirs. The Journal of Canadian Petroleum Technology, 25(2), 1986, pp. 64-67.

[7] Saskoil S.S., Butler R.M.: The Production of Conventional Heavy Oil Reservoirs With Bottom Water Using Steam-Assisted Gravity Drainage. The Journal of Canadian Petroleum Technology, 29(2), 1990, pp. 78-86.

[8] Kasraie M., Ali S.M.F.: Steamflooding Bottom Water Reservoirs. In: Paper SPE SS-87-5, Technical Meeting / Petroleum Conference of the South Saskatchewan Section, Regina, October 6-8, 1987.

[9] Marcio F.C. et al.: The appraisal and development plan for the heavy oil Jubarte field, Deepwater Campos Basin, Brazil. In: Paper SPE 16301, Offshore Technology Conference, Houston, Texas, May 3-6, 2004.

[10] Jayasekera A.J., Goodyear S.G.: The Development of Heavy Oil Fields in the United Kingdom Continental Shelf: Past, Present, and Future. SPE Reservoir Evaluation \& Engineering, 3(5), 2000, pp. 371-379. 
[11] Zhou W., Zhang J. et al.: Key Technologies of Polymer Flooding in Offshore Oilfield of Bohai Bay. In: Paper SPE 115240, SPE Asia Pacific Oil and Gas Conference and Exhibition. Perth, Australia, October 20-22, 2008.

[12] Liu Y., Yang H. et al.: Improve Offshore Heavy Oil Recovery by Compound Stimulation Technology Involved Thermal, Gas and Chemical Methods. In: Paper SPE 20907, Offshore Technology Conference, Houston, Texas, May 3-6, 2010.

[13] Visser R.C.: Offshore Production of Heavy Oil. SPE Journal of Petroleum Technology, 41(1), 1989, pp. 67-70.

[14] Recham R., Osisanya S.O., Touami M.: Effects of water coning on the performance of vertical and horizontal wells-a reservoir simulation study of HassiR'mel Field, Algeria. In: SPE/CIM International Conference on Horizontal Well Technology. Society of Petroleum Engineers, 2000.

[15] Sherrard D.W., Brice B.W. et al.: Application of Horizontal Wells at Prudhoe Bay. SPE Journal of Petroleum Technology, 39(11), 1987, pp. 1417-1425.

[16] Murphy P.J.: Performance of Horizontal Wells in the Helder Field. SPE Journal of Petroleum Technology, 42(6), 1990, pp. 792-800.

[17] Target P.L.: The Haven Oil Field: Development of a Tiny Marginal Field with Horizontal Wells. SPE Journal of Petroleum Technology, 44(4), 1992, pp. 496-501.

[18] Chen H.-K.: Performance of Horizontal Wells, Safah Field, Oman. In: Paper SPE 25568, Middle East Oil Show, Bahrain, April 3-5, 1993.

[19] Shecaira F.S., Branco C.C.M. et al.: IOR: The Brazilian Perspective. In: SPE Paper 75170, SPE/DOE Improved Oil Recovery Symposium, Tulsa, Oklahoma, April 13-17, 2002.

[20] Jurus W.J., Stanko M., Parra A., Golan M.: Simplified Near Wellbore Reservoir Simulation to Predict the Performance of Viscous Oil Horizontal Well With Water Coning From an Active Aquifer. In: SPE Latin American and Caribbean Petroleum Engineering Conference. Society of Petroleum Engineers, 2015.

[21] Verga F., Viberti D., Ferraro P.: Prediction of water coning and water cresting: analytical or numerical models? In: Offshore Mediterranean Conference and Exhibition. Offshore Mediterranean Conference, 2007.

[22] Thomas F.B., Shtepani E., Marosi G., Bennion D.B.: Production Well Water Coning-Is There Anything We Can Do? In: Canadian International Petroleum Conference. Petroleum Society of Canada, 2002.

[23] Tu Xingwan, Dragon L. Peng, Zhaohui Chen.: Research and Field Application of Water Coning Control with Production Balanced Method in Bottom-Water Reservoir. In: SPE Middle East Oil and Gas Show and Conference. Society of Petroleum Engineers, 2007.

[24] Freeborn W., Russell R.B., MacDonald A.J.: South Jenner Horizontal Wells a Water Coning Case Study. Journal of Canadian Petroleum Technology, 29, no. 03, 1990. 
[25] Jin L.: Downhole Water Loop (DWL) Well Completion for Water Coning Control Theoretical Analysis. M.S. Thesis, Louisiana State University, Baton Rouge, LA, Dec. 2009.

[26] Stuebinger L.A., Elphingstone Jr G.M.: Multipurpose wells: downhole oil/water separation in the future. In: SPE Production \& Facilities, Aug 1, 15(03), 2000, pp. 191-195.

[27] Matthews C.M., Chachula R., Peachey B.R., Solanki S.C.: Application of downhole oil/water separation systems in the alliance field. In: SPE Health, Safety and Environment in Oil and Gas Exploration and Production Conference, Society of Petroleum Engineers, 1996.

[28] Peachey B.R., Solanki S.C., Zahacy T.A., Piers K.: Downhole oil/water separation moves into high gear. Journal of Canadian Petroleum Technology, Jul 1, 37(07), 1998.

[29] Peachey B.R. [inventor; Centre for Frontier Engineering Research Institute, assignee]: Multiple cyclone apparatus for downhole cyclone oil/water separation. United States Patent US 5,456,837. Oct 10, 1995.

[30] Amini S., Mowla D., Golkar M., Esmaeilzadeh F.: Mathematical modelling of a hydrocyclone for the down-hole oil-water separation (DOWS). Chemical Engineering Research and Design, 90(12), 2012, pp. 2186-2195.

[31] Stokes D.D., Brew J.R. et al.: Steam Drive as a Supplemental Recovery Process In an Intermediate-Viscosity Reservoir, Mount Poso Field, California. SPE Journal of Petroleum Technology, 30(1), 1978, pp. 125-131.

[32] Lillie W.H.E., Springer F.P.: Status of the Steam Drive Pilot in the Georgsdorf Field, Federal Republic of Germany. SPE Journal of Petroleum Technology, 33(1), 1981, pp. 173-180.

[33] Proyer G., Chaziteodorou G. et al.: Results of a Steamdrive Pilot Project in the Ruehlertwist Field, Federal Republic of Germany. SPE Journal of Petroleum Technology, 37(2), 1985, pp. 284-294.

[34] Jin L.A.: Feasibility Study of Multi-functional Wells for Water Coning Control and Disposal. Ph.D. Dissertation, Louisiana State University, Baton Rouge, LA, Dec. 2013.

[35] Shirman E.I., Wojtanowicz A.K.: More oil using downhole water-sink technology: a feasibility study. SPE Production \& Facilities, Nov 1, 15(04), 2000, pp. 234-40.

[36] Shirman E.I., Wojtanowicz A.K.: Water coning reversal using downhole water sink-theory and experimental study. In: SPE Annual Technical Conference and Exhibition Jan 1, Society of Petroleum Engineers, 1997.

[37] Inikori S.O., Wojtanowicz A.K.: Contaminated Water Production in Old Oil Fields With Downhole Water separation: Effects of Capillary Pressures and Relative Permeability Hysteresis. In: SPE/EPA/DOE Exploration and Production Environmental Conference Jan 1, Society of Petroleum Engineers, 2001. 
[38] Wojtanowicz A.K., Armenta M.: Assessment of Down-Hole Water Sink Technology for Controlling Water Inflow at Petroleum Wells. Journal of Energy Resources Technology. Dec 1, 126(4), 2004, pp. 334-41.

[39] Inikori S.O., Wojtanowicz A.K., Siddiqi S.S.: Water control in oil wells with downhole oil-free water drainage and disposal. In: SPE Annual Technical Conference and Exhibition, Jan 1, Society of Petroleum Engineers, 2002.

[40] Swisher M.D., Wojtanowicz A.K.: New dual completion method eliminates bottom water coning. In: SPE Annual Technical Conference and Exhibition, Jan 1, Society of Petroleum Engineers, 1995.

[41] Jin L. et al.: An Analytical Model for Water Coning Control Installation in Reservoirs with Bottomwater. Journal of Canadian Petroleum Technology, vol. 49, no. 5, May. 2010.

[42] Jin L., Wojtanowicz A.K.: Performance Analysis of Wells with Downhole Water Loop Installation for Water Coning Control. Journal of Canadian Petroleum Technology, vol. 49, no. 6, Jun. 2010.

[43] Jin L. et al.: Scaling Analysis of Wells with Downhole Water Loop Completion for Bottom Water Control. Journal of Canadian Petroleum Technology, vol. 49, no. 11, Nov. 2010.

[44] Jin L., Wojtanowicz A.K.: Coning Control and Recovery Improvement Using In-situ Water Drainage/Injection in Bottom-Water-Drive Reservoir. In: SPE 129663, Proceedings of SPE Improved Oil Recovery Symposium, Tulsa, OK, Apr. 24-28, 2010.

[45] Jin L., Wojtanowicz A.K.: Minimum Produced Water from Oil Wells with Water-Coning Control and Water-Loop Installations. In: SPE 143715, Proceedings of SPE Americas E\&P Health, Safety, Security, and Environmental Conference, Mar. 21-23, Houston, TX, 2011.

[46] Jin L., Wojtanowicz A.K.: Analytical Assessment of Water-free Production in Oil Wells with Downhole Water Loop for Coning Control. In: SPE 141470, Proceedings of SPE Production and Operations Symposium, Oklahoma City, OK, Mar. 27-29, 2011.

[47] Qin W., Luo P., Wojtanowicz A.K.: Improving Oil Recovery in Offshore Heavy Oil Underlain by Large Aquifer. In: SPE Improved Oil Recovery Conference, Apr 11. Society of Petroleum Engineers, 2016.

[48] Qin W., Wojtanowicz A.K., White C.D.: New Cold-Production Technique for Heavy Oil with Strong Bottom Water Drive. In: SPE Journal, Apr 1, 19(02), 2014, pp. 270-279. 